\title{
Antropologia católica e história da Itália
}

\author{
Giovanni Levi \\ Tradução: Sérgio Lamarão
}

1. Enquanto escrevo, a Itália está vivendo uma tormenta clerical, cuja intensidade não parecia mais ser possível numa sociedade que se julgava secularizada. Essa situação, naturalmente, coloca problemas também para os historiadores, talvez excessivamente desatentos às especificidades da sociedade italiana como país católico. Em 1960, Carlo Dionisotti, revelando uma preocupação e uma consciência não compartilhada por muitos outros estudiosos, escrevia:

É difícil, hoje, ter clareza sobre a história que temos vivido e vivemos neste século XX. Porém, é forte a suspeita de que... os eventos dos últimos 50 anos tenham representado uma crise não menos profunda do que aquela que a Revolução Francesa representou na passagem do século XVIII e para o século XIX. Portanto... é preciso ficar atento para os novos elementos da situação atual, que não eram encontrados no passado. Porém, quando fizermos isso - situação em que devemos também calcular o quanto do passado, próximo ou remoto, permanece e pode ainda entrar no jogo -, é preciso, creio eu, renunciar à ilusão de que a tradição leiga tenha raízes ininterruptas e profundas na história da literatura italiana [mas certamente ele também se referia à história italiana tout court]. É preciso, sobretudo, aceitar o fato de que essa história é, por muitos séculos, inseparável - tanto por sua grandeza quanto por sua miséria, não apenas por causa de uma ou de outra - da presença ativa e responsável da Igreja. Se o presente quer estabelecer, sobre fundamentos novos, um paralelo com o passado, deve, como os homens do Renascimento já fizeram no seu tempo e à medida de suas necessidades, lançar fundamentos novos com a vontade e a mente voltadas para o futuro, não podendo ter ilusóes de achar que vai encontrar aqueles fundamentos já estabelecidos e sólidos, de tal forma que basta somente defendê-los. ${ }^{1}$

Essas observaçōes me parecem, ao mesmo tempo, uma advertência e um documento histórico importante, que diz respeito a uma preocupação recorrente diante da presença tão penetrante da essência católica na nossa sociedade, a ponto de ela se ter tornado quase invisível. Quase invisível, como é invisível um fato total e natural, como o ar que se respira.

Não me parece que os historiadores tenham tido uma consciência plena desse problema, não, naturalmente, no sentido de que o catolicismo não tenha sido assumido, sob mil perspectivas, como um aspecto específico da Itália, seja pela sua decadência depois das glórias do Renascimento, seja pela sua liberdade diante do poder do Estado. Mas o que me parece pouco estudado é o tema, que chamaria de antropológico, do caráter político dos italianos daí derivado. Também a hipótese improvável do familismo amoral - isto é, de uma "uma forma particular da relação entre família, sociedade (ou, quando existe, sociedade civil) e Estado, uma forma na qual os valores e os interesses da família se contrapõem àqueles dos outros momentos principais de agregação que identificam uma sociedade democrática", 2 sugerido muitos anos atrás, em 1958, por Banfield, ${ }^{3}$ e retomado recentemente, e com muito vigor, por Paul Ginsborg - é, na realidade, um instrumento pobre e incapaz de dar explicações, porque remete imediatamente à seguinte pergunta: o que gerou o familismo amoral?

Não é por acaso, por outro lado, que parcela significativa da historiografia do Estado moderno tenha prestado atenção sobre períodos anteriores, principalmente os séculos XV e XVI, quando o Estado moderno nascia nas grandes monarquias europeias, deixando a Itália para trás, embora esta tenha sido o lugar de nascimento da modernidade política com Maquiavel e com o republicanismo. A historiografia da Igreja, muitas vezes, também concentrou suas atenções sobre a heresia, as contestações internas e o debate anterior ao Concílio de Trento, e não sobre a Igreja, que veio a se consolidar e a se afirmar no período posterior. Assim, foi conferido mais peso ao agostinismo do que ao tomismo e à segunda escolástica, tanto que, no debate de hoje, muito ativo, sobre a teologia política, os nomes de Tomás de Aquino, de De Soto ou de Francisco Suarez quase não aparecem ${ }^{4}$ 
Penso, portanto, que seria positivo retomar o discurso para indagar não tanto sobre o que foi dito ou pensado em relação ao problema da política e do Estado, ao problema da Igreja e do seu papel direto. Queria propor, por essa razão, algumas indagações, não sobre as relações entre leigos e católicos ou entre instituiçôes do Estado e autoridades eclesiásticas, mas sim sobre os efeitos sobre o senso comum relativo à política e à justiça que a presença paralela do Estado e da Igreja produziu na mentalidade dos cidadáos, convencido de que existe uma antropologia católica que torna o senso comum um terceiro personagem importante na história das relaçôes entre Estado e Igreja.

2. No entanto, uma diferença definida no curso da Idade Moderna entre a concepção protestante e a concepção católica do poder e da sua sacralidade parece-me fundamental. Para os protestantes, naturalmente sob várias perspectivas e com desdobramentos muito variados, há uma ideia essencial: o poder é criado por Deus ou ao menos por aqueles a quem Deus concedeu a soberania. Essas duas alternativas podem conduzir quer a uma forma absoluta de autoridade quer a uma forma constitucionalmente avançada de democracia, mas que são levadas por detrás de uma imagem fortemente carregada de sagrado, investindo poder e instituições. ${ }^{5}$ Só em um país protestante pode-se encontrar, gravada nas cédulas de dinheiro, uma frase como "In God We Trust".

Isso não acontece no mundo católico, o que acarreta consequências muito amplas, que podem ser resumidas seguindo a sistematização dos princípios já definidos por Tomás de Aquino e que Francisco Suarez adaptou em 1612 no Tractatus de legibus ac Deo Legislatore, ${ }^{6}$ atribuindo uma clareza extrema àquilo que a segunda escolástica espanhola tinha elaborado nos 50 anos precedentes. Na verdade, considero Suarez o teórico que escreveu com mais clareza sobre a doutrina política que inspirou as práticas da Igreja do Concílio de Trento em diante.

a. Deus cria os homens sociais e, por isso, com o dever de se atribuírem um governo. "Supposita creatione rationalium creaturarum, lex fuit necessaria necessitate finis, tam simpliciter quam ad melius esse... quia intellectualis creatura eo ipso quod creatura est, superiorem habet cuius providentiae et ordini subiaceat; et quia intellectualis est capax est gubernationis moralis, quae fit per imperium. Ergo connatural est et necessarium tali creaturae ut subdatur alicui superiori a quo per imperium seu legem regatur".?

b. Mas o governo que os homens se atribuem é de sua livre escolha. Esse aspecto vem sendo esclarecido pouco a pouco. Enquanto Tomás de Aquino ainda fala de uma designação divina e Francisco da Vitoria também parece indeciso em relação a esse princípio, de De Soto e do Concílio de Trento em diante a sacralidade do poder é completamente abandonada, sendo confiadas aos homens as responsabilidades em relação quer à escolha da forma de governo quer das leis que não dizem respeito à graça e aos aspectos litúrgicos, seguindo o que já encontramos em Tomás: "lex nova in exterioribus illa solum praecipere debuit vel prohibere, per quae in gratiam introducimur, vel quae pertinent ad rectum gratiae usum ex necessitate"; as outras iudicialia "non cadunt sub praecepto novae legis, sed reliquuntur humano arbitrio". ${ }^{8}$

c. Porém, os homens são pecadores e as formas de governo que se atribuirão serão imperfeitas, a menos que não estejam de acordo com a lei divina e com a lei natural, das quais são aplicações particulares, uma vez que a lei divina e a natural colocam "solum quaedam substatialia fundamenta reipublicae". ${ }^{9}$ Embora as leis humanas sejam imperfeitas, ditadas pelos aspectos sensíveis e pela concupiscência, ainda assim são leis: "inordinatio fomitis non est mere naturalis, sed est poena peccati; et ita dicitur lex tanquam effectus divinae legis". ${ }^{10}$

d. Nenhum outro poder mundano, porém, tem o direito de substituir as formas de governo que os homens se atribuíram, a não ser com o seu acordo e mediante a persuasão. De algum modo, as formas de governo locais precedem aquelas que os Estados modernos nascentes se atribuem: "Contingit autem aliquando sub eodem rege esse plura regna vel plures communitates quasi per accidens, quia re vera inter se non componunt unum corpus politicum, sed ex accidenti diversis titulis in illius potestatem devenerunt, et tunc iniustum esset eisdem legibus diversa regna obligare, si uni essent utilis et non alteri. Quia non comparantur tunc ut bonum commune et particulare, sed ut duo bona communia, quibus per se ac sigillatim propriis legibus prospiciendum est ac si sub diversis regibus permanerent". ${ }^{11} \mathrm{E}$ isso vale também no interior do Estado: "quando vero communitates sunt partes eiusdem regni seu politici corporis, tunc uniuscuiusque partis bonum censetur privatum respectu totius communitatis ad quam leges per se primo feruntur. ${ }^{12}$ 
e. Não obstante, Deus criou um poder, o da Igreja, que representa Cristo na terra e que tem o poder e o dever de intervir, com todos os meios, nos acontecimentos políticos para conduzir os homens, progressivamente, no caminho da salvação: "quia Deus (ut supponimus) specialem congregationem fidelium quae esset unum corpus quod Ecclesiam nunc vocamus, instituit". ${ }^{13}$

Trata-se então, digamos, de uma construção de algum modo aberta e muito livre na primeira parte, confiada ao livre arbítrio dos homens, mas que deixa, na segunda parte, um espaço total à Igreja, moralmente superior e, ela sim, instituída por Deus. Uma Igreja - como recordará um importante documento da Comissão Teológica Internacional, na preparação do Jubileu presidida pelo ainda cardeal Ratzinger ${ }^{14}-\operatorname{tam}^{-}$ bém ela feita por homens e, por conseguinte, por pecadores, mas, enquanto Igreja, infalível e sem pecado.

O poder político é, pois, necessário, mas não sagrado, e retira sua legitimidade da conformidade dos seus comportamentos na busca do bem comum segundo as leis divinas, uma conformidade que, entretanto, é julgada e medida por um poder externo ao poder político que é um poder sacro. À Deus e aos seus representantes pertence tudo, à Cesar uma parte que, porém, é definida, de vez em quando, pela Igreja, que representa Deus na terra. O Estado tem um direito residual, dado como concessão e sempre revogável.

3. Naturalmente tudo isso ainda não quer dizer que a opinião dos teólogos católicos deva ser acolhida ou que tenha sido sempre acolhida pelos governantes. Seria, portanto, simplista resolver a questão afirmando que o avanço da secularização removeria progressivamente essa desvantagem das instituições políticas; o problema, por conseguinte não é fundador, nem diz respeito a um tipo de Estado moderno nem a uma realidade específica. Trata-se, talvez, do indício ou da causa de um atraso na modernidade dos Estados que se envolvem em um conflito com a Igreja. Contudo, não é bem assim.

Isso é um equívoco. O catolicismo é uma religião e uma teologia complexa e às vezes contraditória, é um complexio oppositorum. ${ }^{15}$ Como todas as atividades intelectuais humanas que se ocupam de Deus e da transcendência, a teologia católica também dá continuidade ao esforço de interpretação e de compreensão de alguma coisa de infinito que excede, por definição, as capacidades finitas dos homens. Mesmo quando se renuncia a uma imagem imperscrutável da divindade, a revelação divina permanece, na tradição paulina e agostiniana, uma empresa vivificante que não pode se limitar à literalidade, mas que vê no mundo símbolos e metáforas complexas da divindade que impõem um esforço hermenêutico sem fim. Mas a tradição aristotélica e tomística - que, junto ao Evangelho, põe a corrente da tradição escolástica e dos dogmas o confronto com as ciências - acentua a racionalidade humana e a legibilidade do divino. E é nessa segunda linha de raciocínio que a teoria do direito e do Estado assumida pela Igreja Católica prosseguiu no seu compromisso com as coisas políticas e mundanas, e não somente quando o Papa foi, ao mesmo tempo, pontífice e soberano, como depois do fim do seu poder estatal e temporal. Porém, se o papel de soberano cessou, não cessou, ao contrário, acentuou-se essa dualidade e reforçouse a imagem de si que a Igreja tem de um saber político moralmente superior às práticas dos poderes mundanos. Um equívoco fundamental, porque é impossível dizer quando a Igreja fala de religião ou quando, simplesmente, interfere com uma chantagem moral na vida política dos Estados cuja população seja, por tradição religiosa, católica. Ainda que a Igreja admita um amplo debate teológico no seu interior e, por conseguinte, uma ampla gama de posições quando se trata de teologia e inclua, sob o seu vasto manto, uma extensa variedade de possibilidades, na sua política central propõe políticas mais lineares e uniformes, justificadas muitas vezes exatamente pela necessidade de incluir posiçóes distantes entre si. Um exemplo disso foi a beatificação promovida por João Paulo II, concomitantemente, de dois papas, moral e politicamente muito distanciados entre si, João XXIII e Pio IX.

4. Esses princípios, porém, tiveram muitas consequências na história europeia e admitiram muitas leituras por parte da historiografia. A não sacralidade do poder e a variedade possível das formas de governo, também no âmbito do mesmo império e da mesma nação, por exemplo, foram pouco consideradas, uma vez que 
a imagem weberiana do caminho para a criação do Estado moderno impessoal, racional, legalista, burocrático e nivelador veio a afirmar-se como perspectiva única ou como modelo ou ideal-tipo sem alternativas.

Um modelo único levou à leitura, por exemplo, da história do Império espanhol como a história do fracasso do projeto de adequação a essa perspectiva por parte de Felipe II e de seus sucessores e como causa dos atrasos da modernização espanhola. A historiografia sobre a Espanha, por muitos anos sufocada na pátria do franquismo e dominada pela pesquisa anglo-saxônica, demorou muito tempo para avançar a hipótese de um modelo diferente, católico, de criação do Estado, um modelo no qual o que havia de sagrado era a vontade de adequar-se às prescrições do catolicismo, mas no qual a ideia de uma designação divina era muito mais pálida se comparada ao modelo quase luterano da França, um país cheio de católicos mas não católico. Apenas recentemente a historiografia abriu-se a uma visão mais negocial do projeto imperial, através dos escritos de José Ignacio Fortea Perez, P. Fernandez Albaladejo, Bartolomé Clavero, Antonio Hespana, que sugerem que, tanto na Europa quanto na América, o império ia se constituindo - não por fraqueza, mas sim por projeto - segundo um modelo que julgava dever assumir, pelo menos em parte, ordenamentos que os homens se deram, como objeto de contratação, de modificação progressiva, de negociação, e não através de um modelo de Estado moderno uniforme, imposto do alto. Essa leitura requer, na minha opinião, uma reflexão sobre a própria história da Itália sob o domínio espanhol, visto muitas vezes apenas como causa da decadência, e não também - e sobretudo - como causa da especificidade italiana.

No entanto, o problema central me parece ser outro. A co-presença de dois sistemas normativos, o da Igreja e o do Estado - que não conseguem delimitar com nitidez os seus campos de competência e de autonomia e que não encontraram formas de subordinação da Igreja ao Estado ou vice-versa, como em muitos países de tradição protestante que atribuíram sacralidade ao poder político - teve consequências que não podem continuar a ser lidas nos termos de relações entre Estado e Igreja como instituiçõos, sendo preciso examiná-las sob o aspecto mais geral do efeito produzido em termos de mentalidade. Fala-se, muitas vezes, para a Itália, de debilidade do sistema institucional, que é um modo de se referir ao pouco respeito que os italianos têm pelas instituições públicas e também, no fundo, pelas instituições eclesiásticas.

Uma religiosidade superficial, uma escassa observância dos preceitos religiosos, práticas cujo significado não se conhece e que são repetidas por puro conformismo, são acompanhadas de uma imagem do Estado e de suas instituições mais como um mal necessário, fatal, do qual se deve defender e do qual se deve escapar tão logo seja possível.

5. Paolo Prodi, o mais lúcido e otimista intérprete da história do catolicismo moderno nas suas relaçóes com a política e o Estado, sugere que essa pluralidade de sistemas normativos é o verdadeiro caminho para a liberdade:

O dualismo cristão se transformou em um dualismo das ordens jurídicas concorrentes entre elas (canônica e civil) e em um dualismo entre a esfera da ética (e do direito natural nascente) e a do direito positivo. Uma transformação que investe não somente a vida da Igreja dos tempos modernos, mas também a evolução da constituição política e social do Ocidente e as próprias raízes das liberdades democráticas; uma transformação que permitiu o prosseguimento do dualismo cristão numa forma adequada ao período moderno e, por conseguinte, a colocação em discussão da sacralidade do poder diante das tentativas do Estado moderno, que procurava concentrar soberania e religião, de uma forma quer confessional quer secularizada. ${ }^{16}$

Portanto, esse pluralismo das ordens jurídicas teria desenvolvido um novo dualismo, entre consciência e direito positivo, fruto de liberdade para os indivíduos. ${ }^{17}$ Essa opinião talvez fosse aceitável se a Igreja tivesse querido, quisesse e pudesse aceitar essa posição, e se os dirigentes políticos italianos a tivessem tomado, e a tivessem tomado com coragem. De resto, o dualismo não é pensado como separação de âmbitos, mas talvez de pontos de vista sobre a mesma coisa: "Temos definido assim", afirma Josef Ratzinger, "o dever fundamental da política eclesiástica como eu o entendo: ela deve ter por meta conservar o equilíbrio de um sistema dual que seja fundamento da liberdade. Por isso, a Igreja deve fa- 
zer exigências diante do direito público e não encerrar-se mais no quadro do direito privado" porque "o Estado, com base no seu fundamento ético, remete, para além de si mesmo, a uma outra comunidade. Essa outra comunidade, a Igreja, pensa a si mesma como uma última instância ética" ${ }^{18} \mathrm{O}$ mal já está feito e é velho de muitas centenas de anos e a mesma indefinição sobre onde começa o foro externo e onde termina o interno mostra continuamente essa imagem de liberdade produzida pela co-presença de duas autoridades como algo de todo irreal. $\mathrm{Na}$ minha opinião, aconteceu o contrário. Esse dualismo não resolvido produziu um mecanismo perverso, constituindo nos últimos quatro séculos uma verdadeira antropologia católica, específica da Itália e de outros países católicos, caracterizada exatamente pela debilidade das instituições. Não é por acaso, para dar um exemplo, o sucesso político de Berlusconi. Um representante das instituições, que, na condição de presidente do Conselho, afirma que acha justo fraudar o fisco ou que depenaliza informações falsas sobre os balanços de empresas, não pode ser visto senão de acordo com o seguinte paradoxo: o entusiasmo pela instituição que critica a instituição é uma imagem evidente dessa antropologia, de uma sociedade plasmada pelo dualismo normativo e, portanto, pela ausência substancial de regras seguras.

Pode-se, obviamente, falar de dualismo também para a Igreja. Com uma simplificação à qual já fiz alusão anteriormente, a Igreja também encerra em si duas tradições dificilmente conciliáveis, a agostiniana e a tomista. E não é certo subestimar o fato que tenham nascido exatamente do agostinismo não somente $o$ luteranismo, mas também o jansenismo e outras fases de história da Igreja que colocaram em evidência essa dualidade não sanada. Não sanada, mas resolvida pela presença de uma autoridade única, hierarquicamente indiscutível, ao governo da Igreja e, pois, de uma instituição em condiçōes de ditar regras seguras, de escolher as perspectivas, e de retirar quando lhe apraz a liberdade que o dualismo deveria garantir.

Evidentemente a Itália não é o único país católico. Espanha, Polônia e Croácia etc., na Europa, Chile, Argentina, México, Brasil e outros países latino-americanos viveram histórias diversas, geriram de outra forma as relações entre Estado e Igreja. No entanto, estou convencido de que muitos dos acontecimentos ocorridos nesses países têm uma raiz bem fincada nessa fragilidade institucional, que se traduz, no plano do governo, numa legislação empolada e afobada no esforço de controlar a anarquia da sociedade e que, diante da anarquia, ganhou, não raramente, formas extremas de ditadura.

6. De resto, é o senso de justiça dos cidadãos que é determinado pela debilidade das instituições. Recorrendo-se a uma esquematização extrema, pode-se dizer que toda a história do direito é caracterizada pelo conflito entre a ideia de uma justiça igual para todos, baseada em normas precisas e claras, e a ideia de uma justiça personalizada, de uma lei diferente para todos - porque todos teriam direito a uma justiça que leve em conta o contexto e os acontecimentos biográficos do réu. Se o direito positivo acolheu, progressivamente, a primeira posição, na qual quem tem a soberania, o povo ou o príncipe, determina a lei, deixando aos juízes uma margem reduzida de interpretação da norma a ser aplicada, os sistemas de origem teológica - direito canônico, direito islâmico, direito talmúdico - ampliaram enormemente o âmbito das autoridades e a autonomia dos juízes para distribuir uma justiça sábia, que leve em consideração as condições pessoais do réu e os propósitos morais ou de salvação para quem se distribui a pena. Em muitos casos, porém, também aqui, a presença de duas imagens da justiça - ambas utópicas e, portanto, ambas baseadas na confiança que o senso comum tem na autoridade da lei e dos juízes - produziu um senso de justiça específico, específico em particular a muitas sociedades mediterrâneas, nas quais, exatamente, para parafrasear um debate aberto por Natalia Ginzburg, a justiça do direito positivo, não é "a verdadeira justiça". ${ }^{19}$ As consequências são ainda profundas e estão profundamente enraizadas na mentalidade de um país em que existem dois sistemas normativos não separados e não conciliáveis: o sistema jurídico é frágil, os juízes podem contestar porque "politicamente orientados" ou "porque não objetivos" e a lei torna-se, certamente, frágil, confusa e inimiga. 
7. Acredito que não me distanciarei do tema observando que a ambígua relação entre Estado e Igreja é uma das causas essenciais pelas quais a história da Itália unificada encontrou, e encontra, dificuldades para atribuir-se mitos fundadores: a unidade da Itália foi uma guerra civil também contra o Estado da Igreja e foi a "brecha da Porta Pia" ${ }^{20}$ que marcou a junção das duas partes do país. Entretanto, isso não pôde se tornar um mito fundador da nação; ao contrário, impõe quase que uma embaraçosa necessidade de esquecer. O Risorgimento é imaginado e contado essencialmente como uma guerra contra a Áustria, sendo parcialmente obscurecidos todos os elementos de guerra interna na península. O fascismo também buscou uma improvável mitologia para o seu nacionalismo, mas não no Risorgimento, e sim no Império Romano. Ademais, o nosso país não gosta de guerras civis, que se encontram na base das mitologias nacionais de outras naçóes que construíram o seu orgulho sobre a vitória do bem sobre o mal internamente. É só pensar na Guerra de Secessão americana, ou na Revolução Francesa ou na Revolução Inglesa. É também por isso que a leitura imprópria da Resistência como a guerra de todo o povo italiano contra uma pequena minoria de criminosos - e, portanto, não como uma guerra civil - anulou a possibilidade de utilizar a guerra de libertação como mito fundador da República, uma vez que a interpretação unanimística mostrou, muito tardiamente, a sua improbabilidade. Mas estou convencido que também essa tendência excessivamente benevolente para esquecer os também fortíssimos contrastes que caracterizam boa parte do nosso discurso político encontra suas raízes no sentido incerto do justo e do errado e na sensação inconsciente de que, sendo todos pecadores e todos perdoáveis, não existem princípios fortes em um mundo de instituiçôes débeis.

8. O gênero literário do "escrito em honra de" nunca encontrou uma regra a seguir. Escrevo essas notas para um livro em homenagem a um amigo querido, Tony Molho, seguindo discursos feitos juntos, mais como uma reflexão livre ou uma carta privada do que como a apresentação de algo concluído. Aprendi muitas coisas com ele e com ele compartilhei muitas opiniōes. Compartilhei o seu esforço de entender o mundo mediterrâneo como um mundo fascinante e misterioso, mas, especialmente, como um mundo diferente do resto da Europa e com traços comuns, embora esteja na origem de culturas extraordinariamente diversas. Um mundo fragmentado a interrogar, movido por grupos minoritários empreendedores e móveis. Um mundo em que as prisões teológicas frequentemente esquecidas do comportamento político se encontram em todos os países da borda norte e da borda sul, criando sentidos de justiça e representaçóes das instituições que, muitas vezes, possuem aspectos mais semelhantes do que aquele que estamos habituados a pensar.

Eu observei com grande interesse, já há muitos anos, a sua atenção por um tema extremamente difícil que, ainda hoje, os historiadores têm dificuldade em abordar, o do microcrédito ativado pelos sistemas de dotes.

Mas de uma coisa não estou convencido e este é também o motivo dessas páginas. Não estou convencido de que

o aspecto decisivo da organização política dos Estados no período em questão [trata-se dos séculos XV e $\mathrm{XVI}$ ] não foi a antinomia, usualmente reivindicada, entre centro e periferia, onde o primeiro se reforçava às expensas da segunda; na verdade, centro e periferia se reforçavam mutuamente, num processo de recíproco reforço que conferia ao centro novos poderes jurídicos e administrativos, mas, ao mesmo tempo, consolidava as liberdades tradicionais que as instituições e os corpos da periferia haviam desfrutado no passado. ${ }^{21}$

Se não é apropriado estudar a história política e econômica da Itália como um caso certamente particular de uma criação penosa e incompleta do Estado moderno, encontrando na variedade dos conflitos entre centros e periferias ou nas classes dirigentes centrais e periféricas incompetentes as causas de retardos e desvios, não podemos mais nos referir a elas como um modelo imprescindível de relações entre centro e periferia, que deixa de lado a criação progressiva de um tipo de cidadãos dominados por uma visão estranha e cética a respeito do mundo dos poderes. O modelo de Weber ou de Chabod continua 
sendo um modelo único, em torno do qual os historiadores se propõem a encontrar variações e atrasos, como se faz na música nas variações em torno do tema. Não, não é o sistema fiscal, nem a burocracia nem a guerra que nos darão uma resposta a por que este país é aquilo que é, mas sim a fragilidade - e não o progressivo fortalecimento - das instituições diante do terceiro personagem deixado de lado, inseguro entre a presença ambígua de mais poderes normativos, que são, precisamente, os habitantes deste país. Não se trata de disciplinamento, que também foi o objetivo da Igreja e do Estado, mas antes a indisciplina e a paralisia produzida pela presença equívoca de duas disciplinas. Acredito que, no final, será preciso ter coragem suficiente para se dedicar ao estudo do modelo católico de Estado e da antropologia católica daí derivada. Como, na realidade, Dionisotti sugeria.

\section{Notas}

${ }^{1}$ C. DIONISOTTI, Chierici e laici. In: Geografia e storia della letteratura italiana. Turim: Einaudi, 1967, p. 88.

2 P.GINSBORG, L'Italia del tempo presente. Famiglia, società civile, Stato 1980-1996. Turim: Einaudi, 1998, p.187.

${ }^{3}$ E. BANFIELD, The Moral Basis of a Backward Society. Glencoe, Ill., 1958 (tr. it.Le basi morali di una società arretrata. Bolonha: Il Mulino, 1976). Paradoxalmente, um conceito bastante genérico podia ser aplicado, ao contrário, mesmo a uma sociedade não católica: "Posso entender perfeitamente o que um protestante anglo-saxão experimenta diante da 'máquina papista', toda a antipatia que lhe é possível reunir, quando se dá conta da existência de um monstruoso aparato hierárquico administrativo que quer controlar a vida religiosa, dirigido por homens que recusam, por princípio, ter uma família. Uma burocracia de celibatários, pois. E isso não pode deixar de aterrorizá-lo, dado o seu senso de família e a sua aversão a qualquer controle burocrático". C. SCHMITT, Romischer Katholizismus und politische Form (1923), trad. it. Catollecesimo romano e forma politica. Milão: Giuffré, 1986, p. 32.

${ }^{4}$ Refiro-me, a guisa de exemplo, a dois importantes livros de G. FILORAMO (org.), Teologie politiche. Modelli a confronto. Brescia: Morcelliana, 2005, e P. BETTIOLO-G.FILORAMO (org.), Il Dio mortale. Teologie politiche tra antico e contemporaneo. Brescia: Morcelliana, 2002.

${ }^{5}$ Cf. Q. SKINNER, The Foundations of Modern Political Thought. vol. 2. The Age of Reformation. Cambridge: Cambridge University Press, 1978 (trad. it. Le origini del pensiero politico moderno.vol.2 L'età della Riforma. Bolonha: Il Mulino,1989). ${ }^{6}$ F. SUAREZ, Tractatus de legibus ac Deo Legislatore 1. De natura legis. Madri: Consejo Superior de Investigaciones Cientificas, 1971.

${ }^{7}$ ID., I, III, 3, p. 38.

${ }^{8}$ Sancti THOMAE de AQUINO, Summa Theologiae. Cinisello Balsamo: Edizioni Paoline, 1988, p. 1046.

${ }^{9}$ SUAREZ, op. cit., I, III, 20, p. 61.

${ }^{10}$ SUAREZ, op. cit. I, I, 3, p. 13.

${ }^{11}$ SUAREZ, op. cit., I, VII, 14, p. 142.

12 SUAREZ, op. cit., ivi.

${ }^{13}$ SUAREZ, op. cit., I, III, 20, p. 60.

${ }^{14}$ Memory and Reconciliation: the Church and the Faults of the Past, dezembro 1999. Ver em http://www.vatican.va/roman curia/congregations/cfaith/documents/.

${ }^{15}$ C. Schmitt, op. cit. passim.

${ }^{16}$ P. PRODI, Il Concilio di Trento e il diritto canonico, in G. ALBERIGO-I.ROGGER (org.), Il concilio di Trento nella prospettiva del terzo millennio. Brescia: Morcelliana, pp. 267-285, citado em P. Prodi, Christianisme et monde moderne. Cinquante ans de recherches. Paris: Gallimard Seuil, 2006, pp. 283-4. As citaçōes poderiam, porém, ser multiplicadas, sendo esta uma tese central no trabalho de Prodi.

${ }^{17}$ P. PRODI, op. cit., ivi.

${ }^{18}$ J. RATZINGER, Kirche, “Okumene und Politik. Neue Versuche zur Ekklesiologie, Einsielden, Johannes, 1987 (trad. it. Chiesa, ecumenismo e política. Milão: Edizioni Paoline, 1987, p. 201, cit. In P. PRODI, op. cit., pp. 219-21).

${ }^{19}$ N. GINZBURG, Serena Cruz o la vera giustizia. Turim: Einaudi,1990. Trata-se do caso de uma menina adotada ilegalmente e retirada, pelos juízes, da família que a havia adotado. Ginzburg citava polemicamente A. Galante Garrone, que escrevera: "Aplicar as leis existentes: ou que outra coisa hão de fazer os juízes de todo o mundo? É um princípio universal, presente na Idade Moderna, que triunfou com o Iluminismo e a Revolução Francesa... Me vem em mente aquilo que Salvemini gostava de lembrar: a afiada resposta de um grande juiz americano da Corte Suprema ao advogado que invocava justiça: 'Eu não estou aqui para fazer justiça, mas sim para aplicar a lei”' (La Stampa, 6 de maio de 1989). 
${ }^{20}$ Referência ao episódio que marcou o término do processo de unificação da Itália, em setembro de 1870. Nessa ocasião, as tropas do reino da Itália entraram em Roma exatamente pela Porta Pia, colocando um ponto final no poder temporal do papa (N. do T.).

${ }^{21}$ A. MOLHO, Lo Stato e la finanza pubblica. Un’ipotesi basata sulla storia tardimedievale di Firenze, pp. 225-280, in G. CHITTOLINI, A. MOLHO, P. SCHIERA, Origini dello Stato. Processi di formazione statale in Itália fra medioevo ed età moderna. Bolonha: Il Mulino, 1994, p. 231. Molho remete, a esse respeito, a J. GIVEN, State and Society in Medieval Europe. Gwynned and Languedoc Under Outside Rule. Ithaca, 1990.

\section{RESUMO:}

A presença da essência católica na sociedade italiana é tão penetrante, a ponto de ela se ter tornado quase invisivel, natural, como o ar que se respira. Não é por acaso que parcela significativa da historiografia do Estado moderno tenha dedicado a sua atenção a periodos anteriores, principalmente aos séculos XV e XVI, quando o Estado moderno nascia nas grandes monarquias europeias, deixando a Itália para trás. A historiografia da Igreja, muitas vezes, também concentrou suas atençōes sobre a heresia e o debate anterior ao Concílio de Trento, e não sobre a Igreja que veio a se consolidar no periodo posterior. Seria positivo, portanto, indagar não tanto sobre o que foi dito ou pensado sobre as relaçóes entre leigos e católicos, ou entre instituiçôes do Estado e autoridades eclesiásticas. Quero propor algumas indagaçôes sobre os efeitos sobre o senso comum relativo à politica e à justiça que a presença paralela do Estado e da Igreja produziu na mentalidade dos cidadãos, convencido de que existe uma antropologia católica que torna o senso comum um terceiro personagem importante na história das relaçóes entre Estado e Igreja.

Palavras-chave: catolicismo, sociedade italiana, sistema político, sistema jurídico.

\section{ABSTRACT:}

The essence of the Catholic presence in Italian society is so pervasive to the point it has become almost invisible, natural, as the air we can breathe. It is no coincidence that a significant portion of the historiography of the modern state has devoted its attention to earlier periods, especially the XV and XVI centuries, when the modern state was born in the major European monarchies, leaving Italy behind. The historiography of the Catholic Church, many times, also focused its attention on the heresy and the debate before the Trent Council, and not the Church that came to be consolidated in the later period. It would be good, to ask not so much about what was said or thought about the relationship between laics and Catholics, or between institutions of state and church authorities. I propose some questions about the effects on the common sense on the politicy and justice that the parallel presence of the State and the Church produced in the mentality of people, convinced that there is a Catholic anthropology. It makes common sense the third main character in the relation's story between state and church.

Keywords: Catholicism, Italian society, political system, legal system. 